\title{
Urbanización, precios del suelo y modelo territorial: la evolución reciente del área metropolitana de Barcelona*
}

\begin{abstract}
In European metropolitan areas, the development of networked infrastructures (mainly transport ones) is favouring the widening of urban growth business to much wider territorial areas. In such areas some processes of functional and socio-economic specialization are taking place simultaneously. This paper provides significant data on the accesibility changes produced in the metropolitan area of Barcelona and their correlation with urban growth and activities situation (bringing out the relationship between urbanizing pace and housing and land price increase). Likewise it identifies the appearing of new centrality and social specialization areas. The paper especially alerts on the generating of high-rental self-segregational areas connected by means of highpriced tolls, as well as geographical enclaves with potential marginality associated to retired population moving to old second residence areas.
\end{abstract}

Keywords: accessibility, connectivity to network, situation factors, urban development, land prices.

\section{Resumen}

En las áreas metropolitanas europeas, la construcción de redes de infraestructuras, fundamentalmente las de transporte, está propiciando la extensión de expectativas urbanísticas a ámbitos territoriales cada vez más amplios, en los que se dan simultáneamente procesos de especialización por tipos de usos y de rentas. Este trabajo aporta datos significativos sobre los cambios de accesibilidad producidos en la Región Metropolitana de Barcelona y su correlación con el crecimiento urbano y la localización de actividades, poniendo de manifiesto las relaciones entre el ritmo de urbanización y el incremento de los precios del suelo y de la vivienda. Asimismo, identifica la aparición de nuevos espacios de centralidad y de especialización social. El artículo alerta en particular de la generación de áreas de autosegregación espacial de rentas altas conectadas por peajes elevados, así como de enclaves geográficos de potencial marginalidad asociados al desplazamiento de población jubilada hacia antiguos espacios de segunda residencia.

Palabras clave: accesibilidad, conectividad a la red, factores de localización, urbanización, precios del suelo. 


\section{Contenido y fuentes del artículo}

$\mathrm{E}$ ste artículo tiene por objeto aportar algunas reflexiones sobre transformaciones sociales y territoriales recientes acontecidas en la Región Metropolitana de Barcelona, que apuntan hacia la quiebra de la ciudad polinuclear, equilibrada y con un alto grado de compacidad en sus asentamientos urbanos, la cual constituía el modelo referencial en que se ha sustentado el planeamiento urbanístico desde 1970 y que parecía consolidarse en el entorno del periodo olímpico, como fecha simbólica de referencia.

La mejora de la calidad de vida, de los servicios y dotaciones de los municipios metropolitanos ha sido muy grande desde la reinstauración de la democracia y desde la incorporación a la Unión Europea, debido al significativo aumento de los niveles de renta y a la potente labor de inversión de las instituciones públicas en ese periodo. Y es forzoso recordar la ya conocida tarea de preocupación urbanística y arquitectónica por la recalificación de espacios de toda índole que ha convertido a la ciudad en un obligado referente. Pero junto a esas indudables mejoras, el crecimiento económico ha traído aparejado un proceso creciente de producción de urbanización e infraestructuras cuyas consecuencias comienzan a ser una realidad: incremento exacerbado del precio del suelo, dispersión del modelo territorial, coste de acceso a los servicios e indicios de creación de territorios de marginalidad sobre nuevos fenómenos sociales.

Los datos utilizados para apoyar las tesis sustentadas en este artículo son producto de tres investigaciones sucesivas realizadas por el autor en los últimos años. La primera corresponde a un estudio realizado en 1995 para el Ayuntamiento de Barcelona, en el que se comparaba la accesibilidad entre los distintos lugares de la región antes y después de la enorme inversión en red viaria que se produjo en torno a los acontecimientos olímpicos de 1992, y en el que se buscaba conocer de qué manera esos cambios ha-

\footnotetext{
* Recibido el 2 de diciembre de 2004, aprobado el 29 de marzo de 2005.

** Departamento de Infraestructuras del Transporte y Territorio, Universidad Politécnica de Cataluña. E-mail: manuel.herce@upc.es.
}

bían afectado a las pautas de localización de las principales actividades económicas del sistema urbano (Herce, 1998).

El segundo de los trabajos utilizados, realizado en 2002, consiste en un análisis comparado de la evolución urbanística de las grandes ciudades españolas en los últimos años (Borja et al., 2003). Este estudio estaba orientado principalmente a identificar indicadores de fenómenos nuevos que-de existir-pudieran cambiar los modelos de organización territorial de estas ciudades. Sus bases fueron las diversas fuentes estadísticas de la región y la encuesta metropolitana de comportamiento de la población que se realiza cada cinco años.

La última investigación ha surgido de la preocupación por un fenómeno que tal vez carace de importancia cuantitativa, pero que resulta representativo, sin embargo, de los cambios sociales y espaciales que se están dando en las grandes metrópolis occidentales: la fuerte transformación de la accesibilidad entre los territorios metropolitanos ha repercutido también en incrementos del precio en la ciudad central, y la combinación de este hecho con la destrucción de puestos de trabajo en su tradicional base industrial se ha reflejado en la aparición de un movimiento migratorio relevante de ciudadanos de Barcelona a municipios periféricos, con una importante pérdida de renta de posición y de conexión a los servicios. Este fenómeno marca la aparición de áreas de marginación relativa, destino de una nueva clase social de jubilados de la nueva economía, la cual asume un alto coste de marginalidad o de coste de acceso a los servicios (Herce, 2004).

\section{Breve descripción de la Región Metropolitana de Barcelona}

Para entender mejor la importancia de las mutaciones que se están produciendo en el modelo territorial de Barcelona, se realizará una breve descripción de las características de la Ciudad Metropolitana (M.M.M., 1995). La ciudad de Barcelona está ubicada en el llano conformado por las estribaciones de la sierra de Collserola y el mar, y limitada por las desembocaduras de los ríos Besós y Llobregat; sobre ese mismo llano y en los valles de esos ríos tiene lugar un continuo urbano de alrededor de una treintena 
de municipios, que conforman algunas agrupaciones de administración metropolitana del transporte y el medio ambiente; a esta área inmediata la llamaremos Primera Corona Metropolitana. La población de ese conjunto -Ciudad Central y Primera Corona- se ha mantenido estable sobre los tres millones de habitantes en los últimos veinticinco años.

En ese periodo, el fenómeno de dependencia metropolitana se ha extendido a casi un centenar de municipios que conforman una Segunda Corona Metropolitana de la ciudad, con un radio aproximado de cuarenta kilómetros repecto del centro de Barcelona; estos municipios se localizan sobre los valles existentes al otro lado de la sierra y sobre los corredores que ésta deja en la costa, al sur y al norte del llano de la ciudad. Una característica propia de organización de ese territorio es la existencia de una serie de ciudades medias (de entre 50.000 y 200.000 habitantes) con una larga historia de desarrollo económico y de servicios, que han jugado el papel de capitalidades de las diversas comarcas de la región, dando una característica histórica de organización polinuclear al territorio metropolitano.

La organización de las redes de transporte se ha desarrollado según la propia lógica impuesta por la morfología del territorio; los accesos por carretera y ferrocarril a la ciudad de Barcelona siguen un esquema radial a lo largo de los corredores de la costa y de los dos valles fluviales citados. Hasta los años '70 no comenzaron a cerrarse esas redes con algún eje transversal periférico, y hasta la época olímpica no se construyó el anillo perimetral de la ciudad ni los túneles que permiten superar la barrera de las sierras limítrofes. La red ferroviaria (con la salvedad del ramal de conexión de $30 \mathrm{~km}$ construido en 1972 detrás de la sierra de Collcerola) es prácticamente la misma del siglo XIX, aunque con evidentes mejoras tecnológicas; hay que destacar, sin embargo, que casi el 50\% de las vías básicas de acceso ha sido financiado mediante peajes, aún vigentes.

La superficie de la Región Metropolitana es de aproximadamente $3.000 \mathrm{~km}^{2}$ y su población actual es de 4.390.000 habitantes. El término municipal de la ciudad de Barcelona tiene una superficie de $97,6 \mathrm{~km}^{2}$ y su población actual es de 1.500 .000 habitantes (su máximo fue de casi 1.800 .000 en 1983).
El Área Metropolitana de Barcelona continúa siendo la mayor concentración industrial de España, aunque desde los años '70 ha perdido 21 puntos porcentuales en la ocupación en este sector, como consecuencia de la crisis iniciada entonces en la economía occidental. En la actualidad ha perdido mucho peso la tradicional base industrial metalúrgica y textil, para dar paso a una estructura industrial más diversificada, aunque ya con peso muy inferior al del sector de servicios. Esta transformación económica (mostrada en indicadores de la tabla adjunta) ha seguido un modelo de evolución marcado por la clásica descentralización de las industrias por coronas sucesivas, con predominio creciente del sector servicios en el espacio central.

\section{Indicadores de cambio en el modelo social y territorial}

El impulso de las realizaciones olímpicas -y los procesos de cambio que en ella culminaron- han consolidado una triple transformación del Área Metropolitana de Barcelona, plasmada en su organización territorial en los siguientes términos: a) cambio del modelo económico caracterizado por una base de tipo industrial a un modelo diversificado, en el que se da un predominio creciente del sector servicios y una atención preferente a la mejora de los mecanismos de oferta de factores de localización; b) políticas de fuerte inversión infraestructural que han igualado los niveles de accesibilidad del continuo urbano e incorporado un campo de influencia territorial de la plusvalía generada por la gran ciudad mucho más amplio; y c) transformación de las áreas geográficas de centralidad en el territorio metropolitano, apareciendo nuevos espacios de oportunidad de muy diversas características, donde se han concentrado inversiones de gran potencia organizadora de la metrópolis.

Estos fenómenos son análogos a los que se han producido en otras grandes metrópolis occidentales, constituyéndose en fuente de crecimiento económico y en oportunidades de generación y riqueza. Son pues un dato de partida del análisis, un escenario neutro que puede traducirse territorialmente en muy diferentes modelos sociales y económicos; sea en una ciudad-región equilibrada, basada en una distribución igualitaria de los servicios y de las 
Tabla 1. Evolución de indicadores económicos por ámbitos.

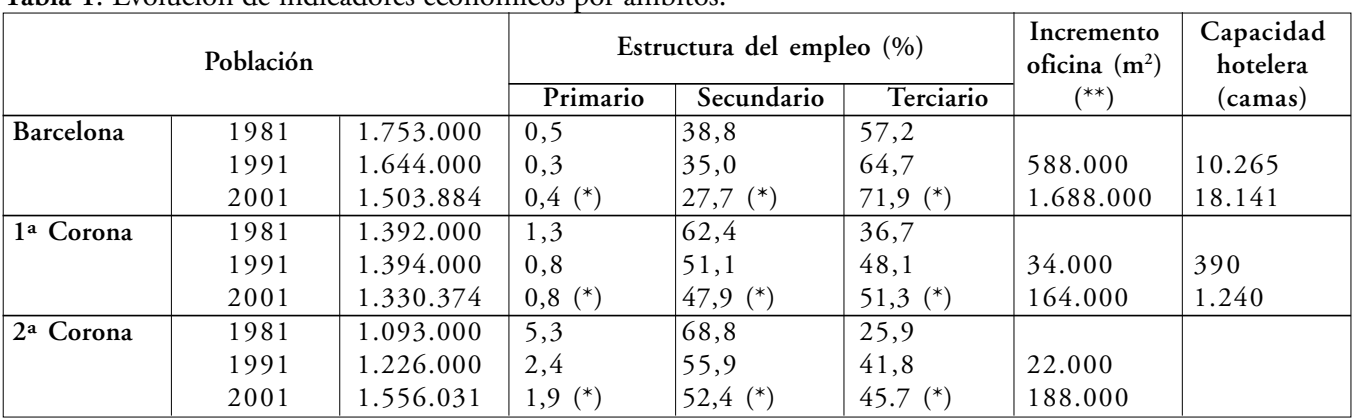

Nota: los datos señalados con $\left(^{*}\right)$ se refieren al año 1996 , los señalados con $\left(^{* *}\right)$ reflejan el incremento en la década anterior.

Fuente: Censos de población (Institut d'Estadítica de Catalunya), Revista Barcelona Economía (Ayuntament de Barcelona) y anuario del Institut de Turisme de Barcelona.

infraestructuras, de forma que ayude a la redistribución espacial de la renta; o por el contrario, en una ciudad dispersa, de altos costes sociales y ambientales, donde prime la rápida producción de plusvalías urbanas. En el ámbito que se analiza pueden encontrarse indicios de coexistencia de ambos fenómenos sin que parezca, por desgracia, que la balanza tienda a inclinarse hacia el lado del primero.

En la tabla 1 se han puesto de relieve los indicadores económicos de ese crecimiento, que muestran el cambio importante de la base económica de la ciudad de Barcelona, convertida en un centro regional de servicios y con un importantísimo papel como destino turístico de primer orden (el sector terciario ha alcanzado ya un $72 \%$ de la población activa; el incremento del techo destinado a oficinas ha sido enorme y se ha disparado la ya importante capacidad hotelera de la ciudad existente antes de las Olimpiadas). Junto a ello se ha dado una progresiva pérdida del rol industrial productivo del continuo urbano de la Primera Corona, con reforzamiento de su carácter residencial; a pesar del estancamiento demográfico de sus municipios en el periodo, el ritmo de construcción de nuevas viviendas ha sido fuerte, con una evolución del precio análoga a la de Barcelona.

Esta transformación ha sido acompañada por un fuerte incremento de la base infraestructural, fundamentalmente carreteras. En el periodo 1985-2000 se han construido $202 \mathrm{~km}$ de autopistas y carreteras y $126 \mathrm{~km}$ de nuevas vías urbanas e interurbanas, con una inversión de casi dos mil millones de euros; es de destacar que en el mismo periodo se ha incrementado la red de transporte de infraestructura fija en tan sólo 13,8 km, con una inversión de poco más de 200 millones de euros (Herce, 2002a).

El resultado ha sido un espectacular crecimiento del suelo urbanizado en toda la región, sin un incremento demográfico que lo sustente; en el periodo 1980-2000 se ha pasado de 22.000 hás de suelo urbanizado en la región metropolitana a 48.500 , con una distribución por ámbitos altamente reveladora de cómo se ha incorporado territorio al ámbito de la plusvalía urbana como principal refugio del incremento de recursos económicos (Serratosa et al. 1998).

Sobre la base de los estudios citados y con uso de esos indicadores, se pone de relieve a continuación el modo en que ese crecimiento se ha plasmado espacialmente, afectando a los factores de localización de las actividades y al propio modelo territorial de la aglomeración metropolitana.

\section{Cambios en la distribución de los niveles de accesibilidad e inicio de un proceso de especialización del espacio}

El crecimiento de la extensión de la red viaria ha producido un incremento generalizado de la accesibilidad en todo el territorio, que se ha traducido en cambios importantes en la distribución del precio del suelo; esto ha afectado a los patrones de localización de las actividades y se ha traducido en una mutación del modelo territorial organizativo de la 
Urbanización, precios del suelo y modelo territorial: la evolución reciente del Area Metropolitana de Barcelona

Tabla 2. Evolución de la superficie urbanizada por zonas (hás.).

\begin{tabular}{|l|c|c|c|c|}
\hline & $\mathbf{1 9 7 2}$ & $\mathbf{1 9 8 6}$ & $\mathbf{1 9 9 2}$ & $\mathbf{2 0 0 0}$ \\
\hline Barcelona & 4.244 & 5.708 & 6.040 & 6.166 \\
\hline Primera corona & 5.316 & 9.979 & 11.430 & 12.386 \\
\hline Total AMB & 9.560 & 15.687 & 17.470 & 18.552 \\
\hline Segunda corona & 7.431 & 20.723 & 26.929 & 30.020 \\
\hline $\begin{array}{l}\text { Total Región } \\
\text { Metropolitana }\end{array}$ & 16.991 & 37.410 & 44.399 & 48.572 \\
\hline
\end{tabular}

Fuente: M.M.M. (1995)

Ciudad Metropolitana. Es curioso observar cómo el incremento del espacio accesible desde el centro metropolitano ha supuesto, de forma paradójica, el reforzamiento de la ciudad como centro metropolitano, con incremento de la dependencia de la periferia más inmediata y creación de una ciudad dispersa y en cierto modo difusa en los municipios más alejados, con fenómenos de especialización espacial análogos a los de otras ciudades.

Para analizar este fenómeno recurriremos a los resultados del primero de los trabajos mencionados anteriormente; en él se creó un indicador de centralidad geográfica que resumiera la accesibilidad combinada de cada nodo del sistema viario al resto de los nodos de la red (combinando con una accesibilidad terminal asociada a la fluidez de los enlaces viarios y al tiempo promedio de aparcamiento en el entorno de cada nodo), se dibujaron las curvas isocronas representativas de ese indicador en la situación anterior a la transformación de la red viaria básica y en el periodo posterior, se detectaron los territorios que habían alterado su posición geográfica en términos de tiempos de conexión y se estudió si existía alguna correlación de ese hecho con la implantación en número relevante de nuevas actividades económicas (Herce, 1983).

En los gráficos adjuntos se muestra la distribución de las curvas isocronas antes y después de la intervención viaria citada; de su comparación se destacan tres conclusiones importantes: a) la igualación de los niveles de accesibilidad en el espacio interior al anillo periférico-Rondas- construido en la ciudad (espacio que alcanza a casi todo el municipio de Barcelona), sin que se haya creado áreas de mayor centralidad dentro de ese espacio; b) la aparición de un espacio en la Primera Corona (a unos $10 \mathrm{~km} \mathrm{del}$ anillo periférico), que ha pasado de una situación de accesibilidad por debajo de la media del sistema (marginalidad geográfica relativa) a otra por encima de la media metropolitana; y c) la importante disminución del territorio cuya accesibilidad estuviera muy por debajo de la media metropolitana; aún así subsisten espacios claramente peor conectados, ubicados lógicamente en las estribaciones de las sierras limítrofes o interiores.

Es importante observar que en los tres tipos de espacios se constata una clara correlación con los cambios habidos en la localización de actividades. En el primer caso (área central) se observa un efecto claro: la extensión de las nuevas implantaciones de oficinas y hoteles, sobre todo en el espacio interior al anillo periférico (aunque limitada a los ejes de alto valor simbólico) con la aparición de nuevas áreas de centralidad terciaria, el acortamiento de las diferencias en los precios relativos del suelo entre las zonas de la ciudad y la generación de nuevas oportunidades de transformación de las condiciones urbanísticas de zonas que antes eran marginales en la ciudad.

En el segundo de los espacios (aquéllos periféricos incorporados a las áreas centrales) es clara su correspondencia con la implantación de más de una veintena de grandes superficies comerciales, fundamentalmente en la cercanía de los enlaces viarios, por ser estas actividades las únicas con escala suficiente para crear un cordón umbilical de conexión a elementos tan complejos (Dupuy, 1991 y 1995).

Pero incluso ese gran crecimiento en la construcción de grandes y medias superficies comerciales, dentro del boom nacional del sector, presenta aspectos diferenciales de ubicación; no sólo Barcelona concentra más cantidad de techo que el resto del centenar de municipios del área, sino que éste está destinado en una gran proporción al sector del comercio ocasional y de mayor precio - cuando no de artículos tecnológicamente avanzados y de lujo-, y con una oferta de ocio muy superior que en las superficies periféricas, centradas en mucha mayor medida en el comercio de artículos de consumo cotidiano. 
Finalmente, la ciudad de la dispersión es un hecho donde los incrementos de accesibilidad han sido importantes en esa Segunda Corona; a pesar del crecimiento de mayor densidad producido en torno a las capitales comarcales, ha sido mucho mayor el producido en los municipios pequeños.

Los indicadores muestran que el uso industrial tiene un enorme crecimiento en la Segunda Corona desde 1970, incrementado en la última década, lo que contrasta con el retroceso constante de este uso en Barcelona y con el estancamiento en su Primera Corona desde 1990. Al mismo tiempo, el crecimiento del suelo de tipo residencial en sus municipios en la última década duplica al del resto del área.

En suma, todos los indicadores analizados presentan una lectura inequívoca: la Ciudad Metropolitana de Barcelona comienza a constituirse con mucha más fuerza que hace treinta años según el modelo de una ciudad central, avanzada económicamente, que concentra la mayoría de las actividades terciarias y gran parte de las dotaciones de ocio, servicios profesionales e instalaciones culturales; rodeada de una corona de municipios donde se refuerza su carácter residencial y su dependencia funcional respecto al centro; y una Segunda Corona de una gran extensión, caracterizada por la dispersión espacial de actividades y la baja densidad. Territorio con creciente especialización del espacio sobre la distribución de valor que le confieren las redes de trasporte, que no es ni mucho menos la ciudad-región formada por un sistema de centros equilibrados que pretende el discurso oficial imperante.

\section{Primer aspecto de la especialización: el reforzamiento de la ciudad central}

Se han citado indicadores que muestran la creciente concentración de actividades terciarias en la ciudad de Barcelona, de forma que la incorporación de suelo urbanizado en gran cuantía en su periferia y el incremento de accesibilidad de la misma se han traducido, paradójicamente, en un reforzamiento de la centralidad de la ciudad. Y es relevante que el fuerte incremento de accesibilidad fuera del perímetro de las Rondas no se haya traducido en análoga medida en producción de espacios de oficinas en la periferia; el incremento de techo terciario no destinado al comercio en el resto del Área ha sido de menos del $22 \%$ del total del producido en Barcelo-

Figura 1. Accesibilidad territorial antes de la red viaria olímpica con curvas isócronas cada 5 minutos (1988).

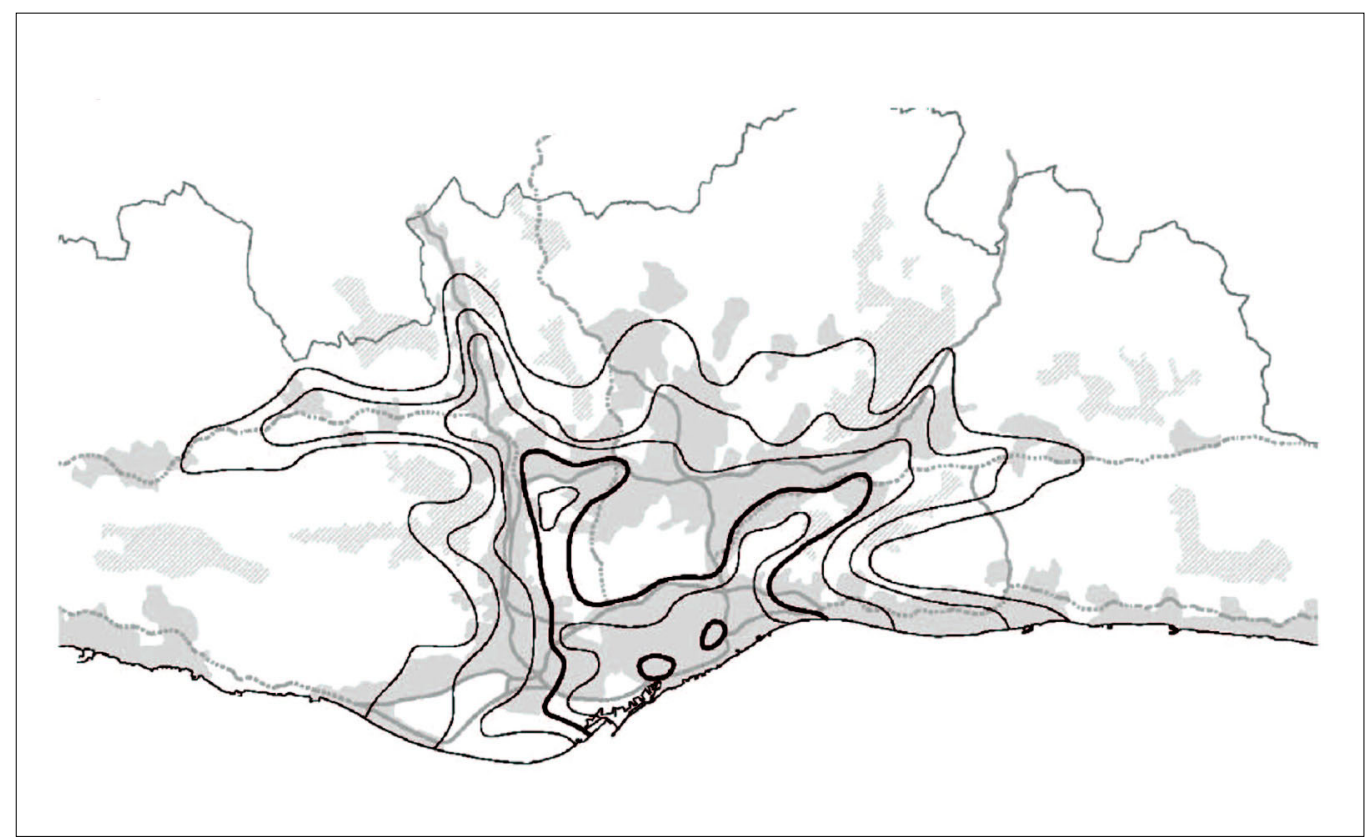

Fuente: elaboración propia. 
Urbanización, precios del suelo y modelo territorial: la evolución reciente del Área Metropolitana de Barcelona

Figura 2. Accesibilidad territorial en la red viaria olímpica con curvas isócronas cada 5 minutos (1992).

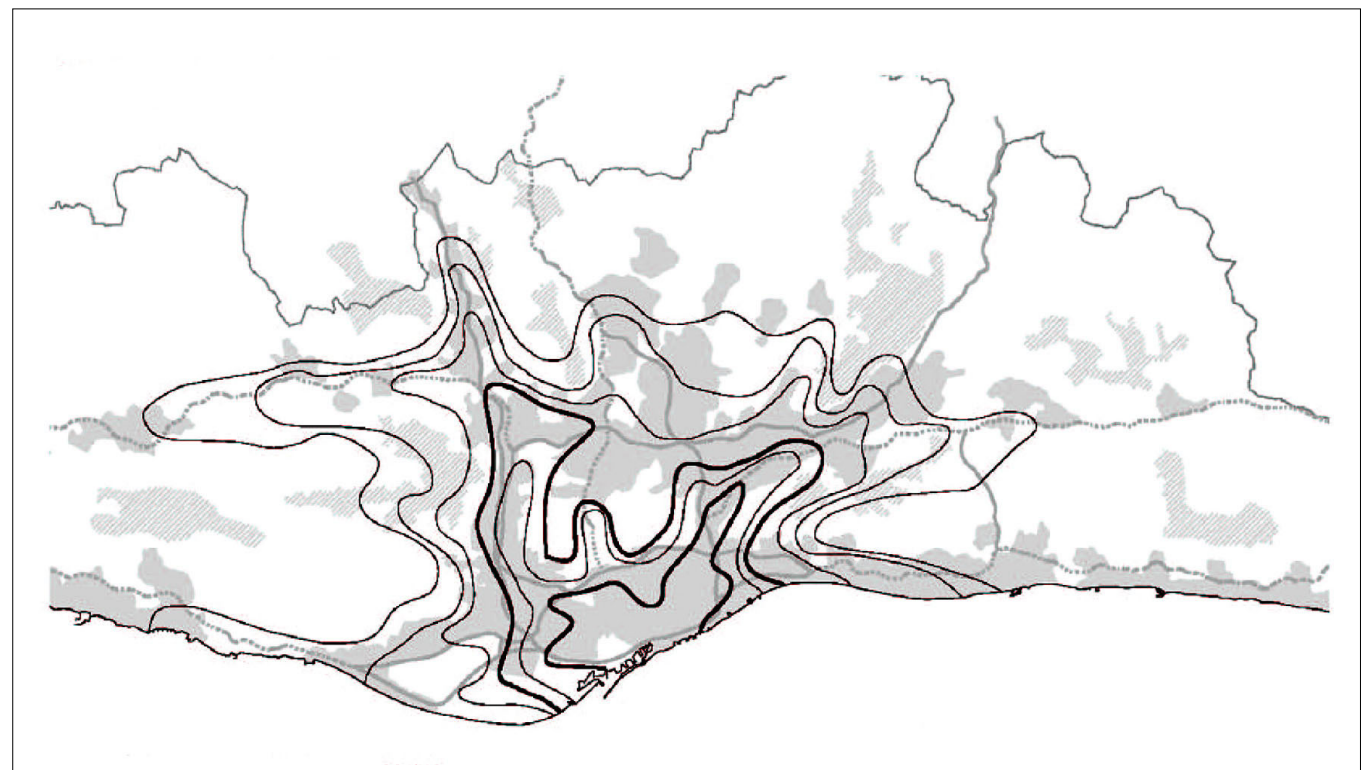

Fuente: elaboración propia.

Figura 3. Áreas incorporadas a la centralidad y localización de actividades.

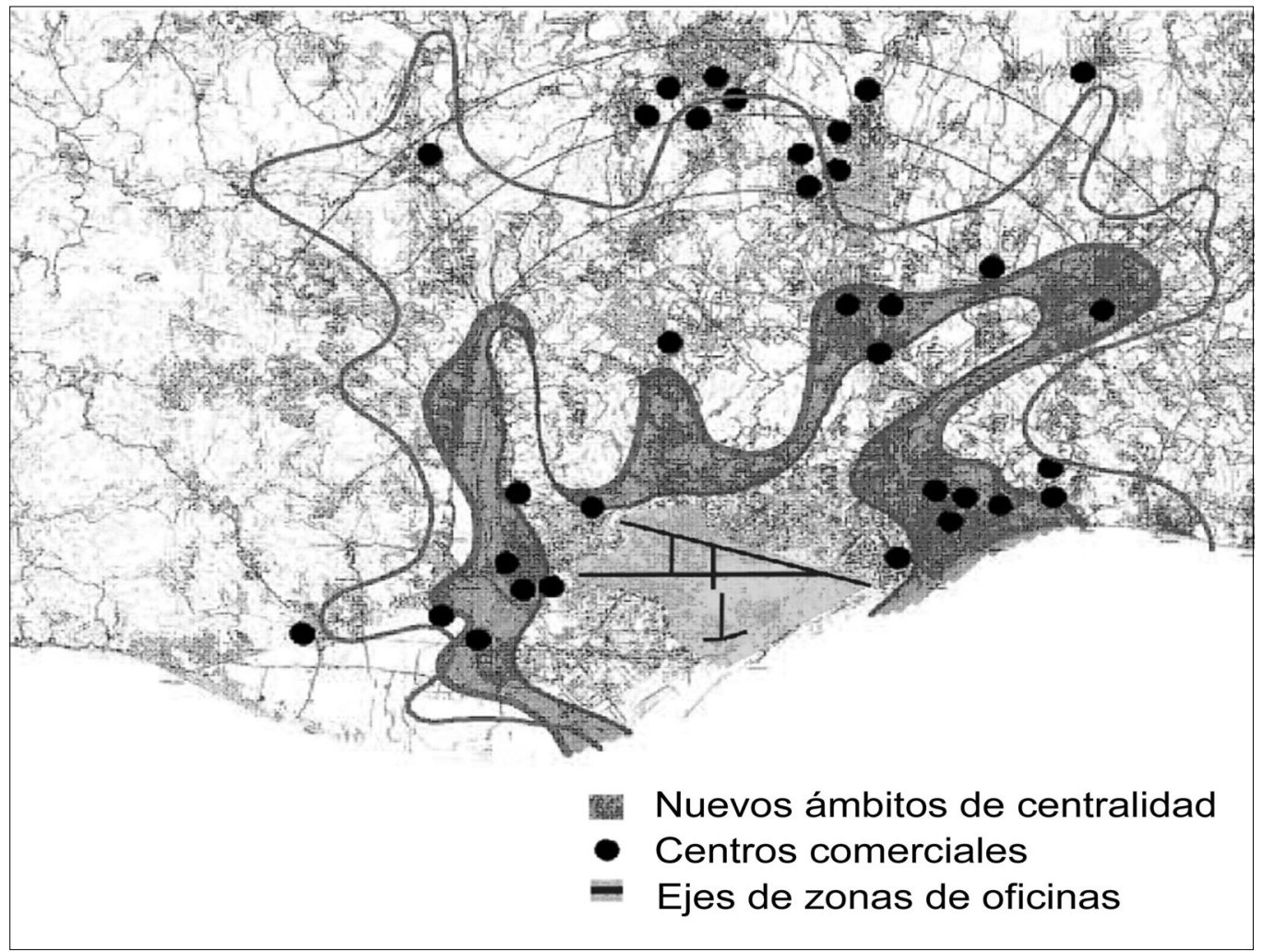

Fuente: Herce (1996). 
Figura 4. Morfología de la región metropolitana de Barcelona.

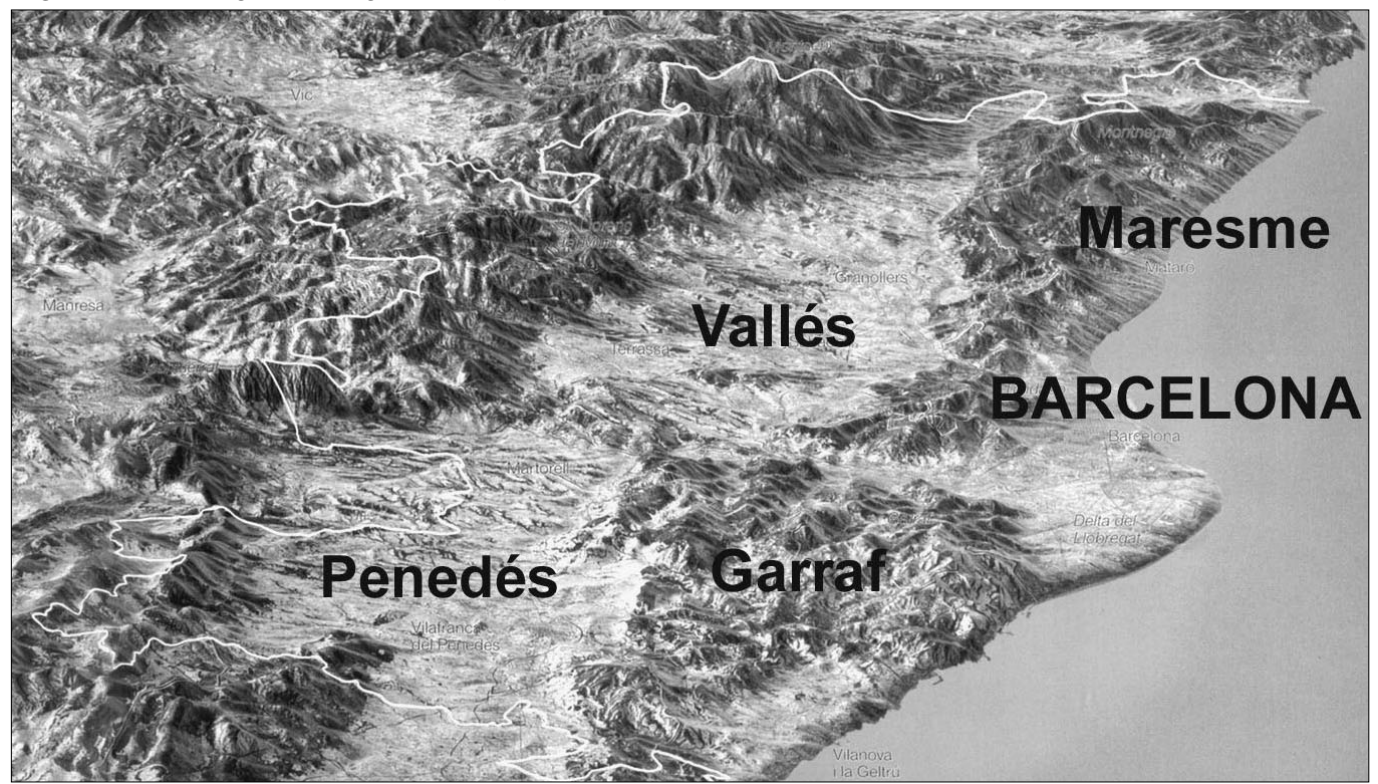

Fuente: M.M.M. (1995).

Tabla 3. Indicadores de centralidad de Barcelona-ciudad.

\begin{tabular}{|l|l|l|l|l|}
\hline \multirow{2}{*}{ Barcelona ciudad } & \multicolumn{2}{c|}{1992} & \multicolumn{2}{c|}{2001} \\
\cline { 2 - 5 } & $\mathbf{M}^{2}$ de techo & Licencias & $\mathbf{M}^{2}$ de techo & Licencias \\
\hline Total servicios & 9.412 .000 & 56.092 & 12.404 .000 & 76.022 \\
\hline Comercio mayorista & 2.988 .000 & 13.029 & 2.720 .000 & 13.937 \\
\hline Comercio minorista & 2.812 .000 & 39.182 & 3.392 .000 & 40.653 \\
\hline
\end{tabular}

\begin{tabular}{|l|c|c|}
\hline $\begin{array}{l}\text { Suelo de grandes y medias } \\
\text { superficies comerciales producido } \\
\text { desde } \mathbf{1 9 8 0}\end{array}$ & Ciudad de Barcelona & $411.020 \mathrm{~m}^{2} \mathrm{t}$ \\
\cline { 2 - 3 } & Resto Región Metropolitana & $365.240 \mathrm{~m}^{2}$ \\
\hline
\end{tabular}

\begin{tabular}{|l|c|c|}
\hline Usuarios de equipamientos lúdicos y culturales de Barcelona & $\mathbf{1 9 9 4}$ & $\mathbf{2 0 0 1}$ \\
\hline Equipamientos culturales & 4.244 .434 & 8.643 .071 \\
\hline Espacios lúdicos & 3.277 .870 & 5.175 .862 \\
\hline Bus turístico & 123.800 & 983.302 \\
\hline
\end{tabular}

Fuente: Revista Barcelona Economía (Ayuntamiento de Barcelona), Encuesta sobre "Activitats y Formes de Vida de la Població a la Regió Metropolitana” (Institut d'Estudis Metropolitans) y Herce (1996).

na (casi 1,7 millones de $\mathrm{m}^{2}$ ), y limitado a las capitales comarcales de esta área (Ferrer, 1992 y 2001).

Es interesante comparar los datos de evolución de las distintas actividades de servicios con la evolución de los hábitos de comportamiento de la población que se deducen de la encuesta metropolitana, tal y como se refleja en la tabla 4 . Y así, hay que destacar el incremento de la dependencia respecto a Barcelona de los ciudadanos del Área Metropolitana en lo que atañe a los servicios y al ocio, incluso en aspectos tradicionalmente más ligados al municipio como restaurantes, bares y discotecas; también es significativo que desde 1990 se haya duplicado el porcentaje de ciudadanos que compra vestido y calzado en Barcelona, lo que evidentemente es consecuencia en gran parte del incremento de renta de los ciudadanos, pero no deja de ser un indicador de dependencia comercial de esa ciudad y de la pérdida relativa de calidad del comercio local en los municipios de la periferia. 
Urbanización, precios del suelo y modelo territorial: la evolución reciente del Area Metropolitana de Barcelona

Tabla 4. Evolución de la movilidad y dependencia espacial de los ciudadanos de la periferia.

\begin{tabular}{|l|l|c|c|c|}
\hline \multicolumn{2}{|c|}{ Modo de viaje al trabajo } & $\mathbf{1 9 9 0}$ & $\mathbf{1 9 9 5}$ & $\mathbf{2 0 0 0}$ \\
\hline \multirow{3}{*}{ Parcelona } & Transporte público & $36,7 \%$ & $35,4 \%$ & $36,3 \%$ \\
\cline { 2 - 5 } & Transporte privado & $36,4 \%$ & $34,3 \%$ & $41,7 \%$ \\
\hline & Transporte público & $24,8 \%$ & $41,2 \%$ & $23,8 \%$ \\
\cline { 2 - 5 } & Transporte privado & $48,5 \%$ & $21,1 \%$ & $52,0 \%$ \\
\hline
\end{tabular}

\begin{tabular}{|l|c|c|c|}
\hline Trabajo de habitantes de la periferia & $\mathbf{1 9 9 0}$ & $\mathbf{1 9 9 5}$ & $\mathbf{2 0 0 0}$ \\
\hline En Barcelona & $29,9 \%$ & $30,3 \%$ & $31,9 \%$ \\
\hline En el propio municipio & $40,8 \%$ & $36,4 \%$ & $30,7 \%$ \\
\hline En resto Área Metropolitana & $26,2 \%$ & $28,5 \%$ & $32,6 \%$ \\
\hline
\end{tabular}

\begin{tabular}{|l|c|c|c|}
\hline Hábitos consumo de los ciudadanos de periferia & $\mathbf{1 9 9 0}$ & $\mathbf{1 9 9 5}$ & $\mathbf{2 0 0 0}$ \\
\hline Compra ropa y calzado en Barcelona & $8,2 \%$ & $10,2 \%$ & $17,7 \%$ \\
\hline Va a bares y discos a Barcelona & - & $7,5 \%$ & $11,6 \%$ \\
\hline Va a teatro y museos de Barcelona & - & $15,2 \%$ & $20,5 \%$ \\
\hline Va a restaurantes de Barcelona & - & $7,8 \%$ & $14,6 \%$ \\
\hline
\end{tabular}

Fuente: Encuestas sobre "Activitats y Formes de Vida de la Població a la Regió Metropolitana" (Institut d'Estudis Metropolitans) y Encuesta Metropolitana de Movilidad, Entitat Metropolitana del Transport.

Esta transformación puede ser beneficiosa para la ciudad en un contexto de globalización de la economía y de competencia por la atracción de inversiones, y de esa creación de riqueza la periferia metropolitana no puede salir más que beneficiada (ya en la actualidad, comienzan a extenderse estas actividades sobre áreas bien comunicadas de los municipios inmediatos). Pero hay que retener el dato de la concentración en el espacio central metropolitano, porque conviene tener presentes también los riesgos de conversión de la ciudad central en un inmenso CBD de servicios y turismo, con pérdida progresiva de la función residencial; un somero ejemplo de los costes que ello puede representar es el hecho de que ese reforzamiento de centralidad (asociado a la poca inversión en los sistemas metropolitanos de transporte público) ha supuesto que en estos momentos atraviese diariamente la frontera municipal de la ciudad un volumen de 1.117 .000 vehículos privados, un $75 \%$ más que hace veinte años (655.300 veh/ día) (Área de Mobilitat, Transport i Circulació del Ajuntament de Barcelona, varios años).

\section{Incremento de la renta y de la dependencia en la primera corona metropolitana}

Como se ha mostrado en las cifras de las tablas anteriores, la primera periferia metropolitana fue el espacio de crecimiento primordial hasta mediados los años '80, fue el espacio de localización de la industria durante los treinta años anteriores y cons- tituyó por mucho tiempo la zona suburbial con mayores carencias del ámbito metropolitano. Desde la restauración de la democracia y el ingreso en la Unión Europea ha sido espectacular la transformación urbanística y de los niveles de renta de esos municipios.

Más recientemente, el reforzamiento del papel central de la ciudad de Barcelona (con una alta dependencia de consumo de esta periferia con respecto a ella), asociado al incremento de la descentralización del uso industrial a la Segunda Corona, siguiendo los procesos clásicos de concentración-expulsión que configuran la localización de este tipo de usos, ha propiciado un progresivo proceso de conversión en tejido residencial de gran parte del suelo urbano de la Primera Corona Metropolitana. La Primera Corona ha producido 6.300 hectáreas de suelo urbanizado en los últimos treinta años, y de ellos menos de un tercio ha sido de tipo industrial; pero visto este crecimiento por periodos, el porcentaje de suelo industrial respecto al crecimiento total ha ido bajando del $57 \%$ de la década de los ' 80 a escasamente el $17 \%$ en la de los ' 90 .

La estructura de actividad en la Primera Corona, que suponía un $70 \%$ en el sector industrial en 1970, y todavía era del $51,1 \%$ en 1991 , ya ha pasado a tener mayor componente terciaria desde 1996, pero es un sector servicios ligado casi exclusivamente al consumo, como lo prueba el incremento de grandes superficies comerciales, la trasformación de gran parte de su suelo industrial en áreas de comercialización y 
distribución y los datos de la baja producción de oficinas en esa zona (escasamente un 10\% de oficinas más que en Barcelona), así como el pobre incremento del sector hotelero.

El hecho de la transformación residencial de la Primera Corona no es en sí mismo bueno ni malo, y se traduce en un incremento de su valor, manifestado en acoger usos propios de mayor precio del suelo y en expulsar actividades industriales y otras de tipo más suburbial. Pero lo que sí es relevante para la organización territorial es la escasa capacidad de ese territorio para acoger actividades centrales, y su creciente dependencia de lugares de trabajo fuera del municipio y de tipo cultural, lúdico e incluso comercial de la Ciudad Central, manifestada en el incremento de viajes a ella antes mencionado, agravado por su dependencia del vehículo privado, tal y como se muestra en la tabla 5.

Junto a los indicadores ya analizados, tiene interés observar la evolución de los niveles comparados de renta entre ámbitos territoriales. La evolución de los índices de capacidad económica por zonas de la Región Metropolitana ha sufrido un significativo acortamiento de tramos en toda la región, incluso entre los barrios de Barcelona y entre los municipios metropolitanos; el índice de Gini, que se utiliza para medir la desigualdad de la distribución, ha decrecido también en todos los ámbitos, lo que confirma que la distribución de la capacidad económica se ha hecho más homogénea, pero aun así, este decrecimiento del índice se estanca desde 1995 en la Primera Corona, lo que podría estar señalando la aparición de bolsas de población desfavorecida.

Estos datos quizás sean tan sólo coyunturales, porque no se dispone de datos posteriores sobre la renta familiar disponible, pero señalan la necesidad de prestar atención a su evolución; ya desde 1996 sorprende el incremento de renta en la Segunda Corona y de su distanciamiento respecto a la Primera Corona.

\section{Segunda Corona y ciudad dispersa}

La evolución del uso industrial en el Área Metropolitana en los últimos años muestra su enorme crecimiento en la Segunda Corona desde 1972; pero así como puede observarse un retroceso constante de este uso en la ciudad de Barcelona durante todo ese periodo, por transformación a usos de mayor valor económico, no será hasta 1990 que el ritmo de crecimiento se amortigüe hasta su casi estancamiento en la Primera Corona, manteniéndose e incrementándose sin embargo en la Segunda. La diversidad de fuentes utilizadas sobre este indicador, con métodos de medición no homogéneos, no permite asegurar el valor exacto de esos ritmos de

Tabla 5. Evolución del uso del transporte en la Primera Corona.

\begin{tabular}{|l|c|c|c|}
\hline & $\mathbf{1 9 9 0}$ & $\mathbf{1 9 9 5}$ & $\mathbf{2 0 0 0}$ \\
\hline Viajes en transporte público & $24,8 \%$ & $23,8 \%$ & $21,1 \%$ \\
\hline Viajes en transporte privado & $41,2 \%$ & $48,5 \%$ & $52,0 \%$ \\
\hline Tiempo de viaje en transporte público & $38,4 \mathrm{~min}$ & $40,3 \mathrm{~min}$ & $41,8 \mathrm{~min}$ \\
\hline Tiempo de viaje en transporte privado & $23,5 \mathrm{~min}$ & $21,1 \mathrm{~min}$ & $20,5 \mathrm{~min}$ \\
\hline Tiempo promedio de viaje & $24,2 \mathrm{~min}$ & $24,5 \mathrm{~min}$ & $25,4 \mathrm{~min}$ \\
\hline
\end{tabular}

Fuente: Encuesta Metropolitana de Movilidad, Entitat Metropolitana del Transport.

Tabla 6. Evolución de la renta familiar por ámbitos.

\begin{tabular}{|l|l|c|c|c|c|}
\hline \multicolumn{2}{|c|}{} & $\mathbf{1 9 8 5}$ & $\mathbf{1 9 9 1}$ & $\mathbf{1 9 9 6}$ & $\mathbf{2 0 0 0}$ \\
\hline \multirow{4}{*}{ Renta familiar per cápita } & Barcelona & 769.600 & 1.620 .000 & 1.954 .200 & \\
\cline { 2 - 6 } & Primera Corona & 571.200 & 1.204 .000 & 1.702 .900 & \\
\cline { 2 - 6 } & Segunda Corona & 693.182 & 1.301 .000 & 1.838 .400 & \\
\hline \multirow{3}{*}{ Índice capacidad económica } & Barcelona & 100 & 100 & & 100 \\
\cline { 2 - 6 } & Primera Corona & 74,3 & 77,1 & & 85,3 \\
\cline { 2 - 6 } & Segunda Corona & & 79,8 & & 94,3 \\
\hline \multirow{3}{*}{ Indice distribución de Gini } & Barcelona & 0,437 & 0,413 & & 0,384 \\
\cline { 2 - 6 } & Primera Corona & 0,376 & 0,336 & & 0,338 \\
\cline { 2 - 6 } & Segunda Corona & & 0,341 & & 0,360 \\
\hline
\end{tabular}

Fuente: M.M.M. (1995) y estudio sobre la evolución de la renta familiar disponible, Institut d'Estadística de Catalunya. 
ocupación, pero la tendencia es clara al observar los mapas de evolución de usos del suelo en ese periodo; de otro lado, el estudio antes citado de evolución de los índices de accesibilidad en la Región Metropolitana producido por esas inversiones en red viaria, muestra una clara correlación entre los espacios con incremento sustancial de aquel y la localización del desarrollo urbanístico.

Tal y como se observa en la tabla 3, la producción de suelo urbanizado en la Segunda Corona ha sido la más alta de la Región Metropolitana en los últimos veinte años (casi cuatro veces la del resto del ámbito); de las 3.000 hectáreas de suelo industrial producido en ese periodo, el $70 \%$ lo ha sido en ese ámbito, y de las casi 18.000 de suelo residencial, el $60 \%$ lo ha sido también en esta Corona.

Los municipios de la Segunda Corona han incrementado su población a tasas anuales medias del 2,2\% en los últimos veinte años y del 2,7\% en la última década, mientras la del conjunto metropolitano ha sido escasamente del $0,3 \%$, con pérdida de población de Barcelona y estancamiento en la Primera Corona. Pero lo sorprendente es que en la mayoría de la treintena de municipios de aquel área con mayor crecimiento demográfico (con tasas superiores al $4 \%$ anual acumulativo) ha sido muy inferior la producción de viviendas en ese periodo; y cuando se indaga con más detalle en sus estadísticas se comprueba que la mayoría son municipios con grandes cuantías de las urbanizaciones de segunda residencia, de origen en procesos fuera de la legalidad y de autoconstrucción dados en los años ' 60 y '70 (véase tabla 8).

El tipo de crecimiento en esos municipios y los indicadores de destino del nuevo suelo urbanizado son los típicos de producción de un modelo de ciudad dispersa (el arquetipo edificatorio es el de vi- viendas pareadas), y los de evolución del precio y características de la vivienda, apuntan en el mismo sentido, tal y como se muestran en los planos adjuntos (Font y Lloop, 1999).

\section{Urbanización e incremento de precio del suelo y de la vivienda}

La ciudad se ha hecho enorme en las dos últimas décadas; casi sin crecimiento de población se ha duplicado el suelo urbanizado existente. Desde 1980 se ha pasado de un indicador de $52 \mathrm{~m}^{2}$ totales urbanizados por habitante en el conjunto metropolitano a 110 en 2000, lo que es reflejo fundamentalmente del fuerte ritmo de construcción de nuevas viviendas, superior al de épocas anteriores, con una evolución del precio de las mismas análoga en la Primera Corona y en Barcelona (que se dispara en el último cuatrienio en esta ciudad). Fenómeno éste también lógico, en cuanto este espacio recibe la onda de influencia del crecimiento físico del Área y refuerza su posición central geográfica con las operaciones de reforma de la red viaria regional.

El encarecimiento de precios producido en la totalidad de la ciudad y de su primera corona puede parecer paradójico a los teóricos de la simple aplicación (ingenua) de la ley de oferta-demanda de suelo a este campo, que creen que el mero incremento de suelo urbanizado sirve para abaratar el precio final de la vivienda... El hecho es que sin incremento demográfico, habiéndose más que duplicado la superficie de suelo urbanizado, la vivienda se ha encarecido en valores absolutos un $550 \%$ en esos veinte años. Esto pone de relieve que son otros los factores que configuran el precio de la vivienda (como por ejemplo el refugio del ahorro, la bajada de tipos de interés y la entrada de euros emanada de la unificación de moneda, con una presencia relevante de "di-

Tabla 7. Evolución del precio de vivienda (pesetas $/ \mathrm{m}^{2}$ de techo construido).

\begin{tabular}{|l|c|c|c|c|c|}
\hline & $\mathbf{1 9 8 5}$ & $\mathbf{1 9 9 0}$ & $\mathbf{1 9 9 4}$ & $\mathbf{2 0 0 0}$ & $\mathbf{2 0 0 4}$ \\
\hline Barcelona & 103.000 & 204.000 & 265.000 & 480.000 & 660.000 \\
\hline $1^{\text {a } C o r o n a: ~ D e l t a ~ L l o b r e g a t ~}$ & 65.000 & 178.000 & 181.000 & 300.000 & 380.000 \\
\hline $1^{\text {a } C o r o n a: ~ L l o b r e g a t ~ n o r t e ~}$ & 52.000 & 136.000 & 142.000 & 260.000 & 320.000 \\
\hline $1^{\text {a } C o r o n a: ~ S a n t ~ C u g a t ~}$ & 95.000 & 186.000 & 217.000 & 390.000 & 530.000 \\
\hline $1^{\text {a }}$ Corona: resto Vallés & 50.000 & 136.000 & 134.000 & 240.000 & 320.000 \\
\hline $1^{\text {o } C o r o n a: ~ B e s o ́ s ~}$ & 58.000 & 150.000 & 154.000 & 275.000 & 350.000 \\
\hline
\end{tabular}

Nota: el cambio a euros es de 166,387 pesetas/euro.

Fuente: Dinámicas Metropolitanas ((Mancomunitat Metropolitana de Municipis, 1995), Càmara de la Propietat de Barcelona, Associació de Promotors constructors de Barcelona (APCE) y Herce (2004). 
Imagen 5. Valor remanente del suelo en relación al precio de la vivienda.

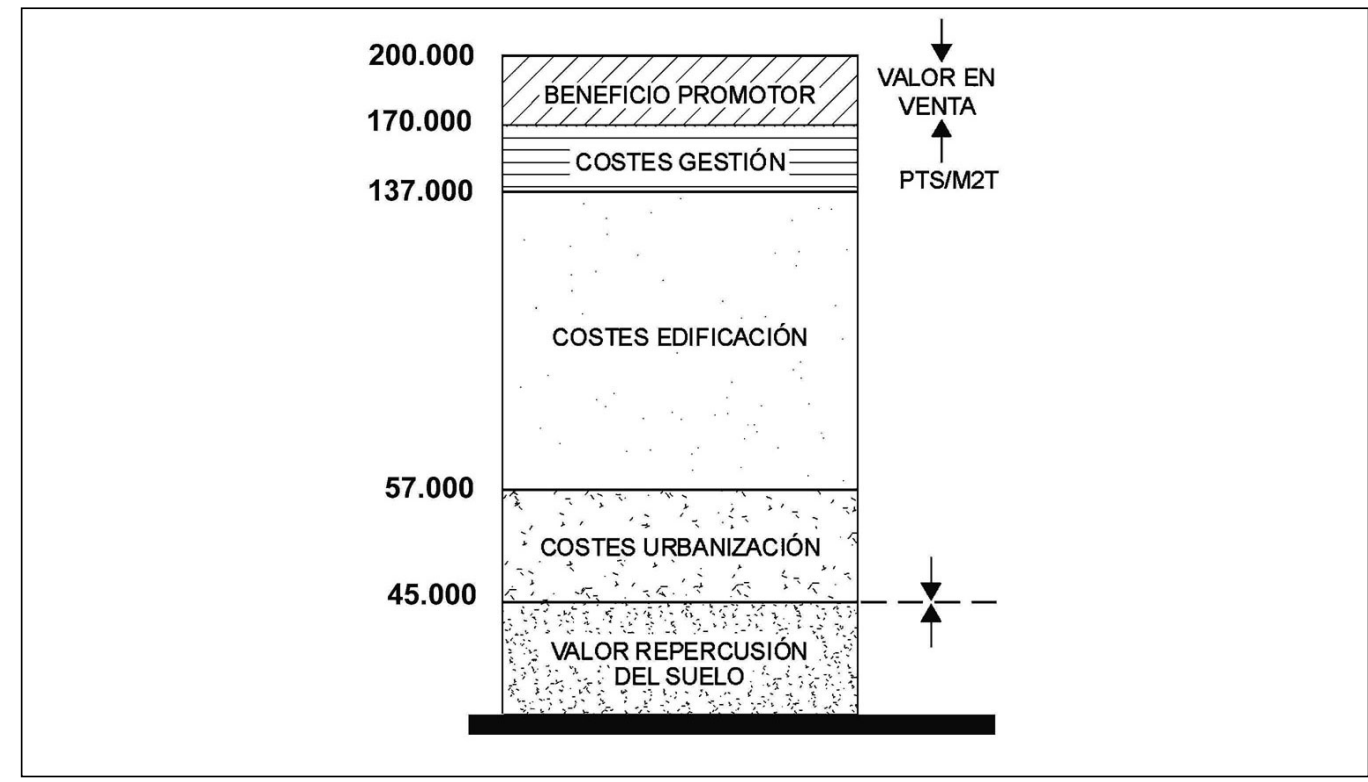

Fuente: elaboración propia.

nero blanqueado"); y que esta alza del precio de la vivienda (por una demanda no generada por las necesidades sociales de ésta) se trasmite automáticamente al precio del suelo, que se fija como valor remanente del precio de venta de la vivienda descontados sus costes de producción, tal y como se muestra en el gráfico siguiente (Roca Cladera, 1987; Herce, 2002b).

La repercusión de ese crecimiento de precio y suelo sobre la ciudad de Barcelona enfatiza la vieja hipótesis de Mayer (1965) conforme el precio se forma de fuera hacia dentro de la ciudad; son las tensiones especulativas sobre terrenos puestos en valor por el acortamiento de tiempo producido en la periferia con las nuevas carreteras las que incrementan fuertemente el precio en estas áreas, y conforman una onda que se transmite hacia el centro, incrementando también el precio de éste. Todos los ejemplos que puedan buscarse en la evolución reciente de las ciudades occidentales corroboran esta tesis.

Finalmente, conviene destacar un último indicador del tipo de ciudad que se está produciendo y de su influencia sobre el precio de las vivienda; el gran aumento, en toda Cataluña, del tamaño medio de los planes parciales de promoción privada, que en la actualidad supera en muchos casos las 100 hectáreas, con densidades brutas cuyos promedios se sitúan sobre las 40 viviendas por hectárea, como consecuencia de una desacertado límite legal y su traducción exacerbada en un planeamiento urbanístico para el que aparentemente la densidad es un mal. El tamaño de la promoción pudiera ser, en teoría, una ventaja para ayudar a resolver saltos de umbrales y deficiencias infraestructurales de los municipios; pero en la práctica no son más que el reflejo de la concentración de la promoción en pocas manos, en un proceso de tipo oligopolista que puede terminar por dictar las reglas de conformación del modelo territorial, máxime cuando los interlocutores son unos Ayuntamientos caracterizados por su poca fortaleza institucional y profundamente dependientes, a corto plazo, de los ingresos derivados de esas promociones.

\section{Autopistas, peajes y nuevos espacios de segregación de rentas}

El actual modelo de desarrollo está basado en la constante producción de infraestructuras, aunque es imposible la consecución de un territorio absolutamente homogéneo e isótropo, y la consecuencia de esa indiscriminada ampliación de las redes-que 
en el fondo busca la extensión de las plusvalía urbana- es la generación de una ciudad dispersa, de un altísimo coste de suministro de servicios.

Es curioso observar cómo la mayor parte de las inversiones en infraestructuras se han guiado por un aparente objetivo de "reequilibrio territorial", y lo que han propiciado es la aparición de la ciudad dispersa y de baja densidad en contraposición al reforzamiento de la ciudad densa en ensanche de las capitales comarcales, colaborando de esta forma a la ruptura del modelo urbanístico equilibrado de referencia. Pero tiene interés comprobar que la extensión generalizada de plusvalía por el territorio está provocando la aparición de una especialización te- rritorial, donde el juego de la alteración del precio del suelo tiene un alto papel discriminador.

En Barcelona y su Área Metropolitana se han vendido casi 100.000 pisos de segunda mano en estos veinte años; desde 1991, 235.000 ciudadanos han desplazado su residencia fuera de la ciudad, una parte de ella empujados por la realización del activo económico que significó la venta de su vivienda revalorizada por los fuertes incrementos del precio del suelo (el 12\% anual acumulativo en la última década). No es posible sostener el tópico de regreso al mundo rural de origen de esa clase trabajadora jubilada: sólo el 11\% de esos desplazamientos de residencia han sido al resto de España, mientras el

Tabla 8. Incrementos demográficos en espacios de ubicación tradicional de urbanizaciones de 2a residencia .

\begin{tabular}{|l|c|c|c|c|c|c|c|c|}
\hline & \multicolumn{3}{|c|}{ Población censada } & \multicolumn{2}{c|}{ Tasa anual Crecimiento } & \multicolumn{2}{c|}{ Parque vivienda (1991) } & Inmigrados \\
\hline Ámbito & $\mathbf{1 9 9 1}$ & $\mathbf{1 9 9 5}$ & $\mathbf{2 0 0 1}$ & $\mathbf{9 1 - 9 5}$ & $\mathbf{9 5 - 0 1}$ & Permanente & $\begin{array}{c}\mathbf{2}^{\mathbf{a}} \\
\text { residencia }\end{array}$ & $\begin{array}{c}\text { Barcelona } \\
(\mathbf{1 9 9 1 - 2 0 0 1 )}\end{array}$ \\
\hline Montnegre & 16.698 & 21.379 & 34.122 & 1,06 & 1,10 & 6.889 & 11.814 & 6.400 \\
\hline Garraf-Ordal & 13.042 & 20.769 & 35.107 & 1,12 & 1,12 & 14.180 & 7.155 & 5.425 \\
\hline Montserrat & 31.770 & 32.268 & 65.131 & 1,00 & 1,15 & 14.283 & 13.293 & 3.670 \\
\hline Vallés-Montsn. & 49.217 & 63.510 & 92.791 & 1,07 & 1,08 & 19.460 & 13.215 & 13.800 \\
\hline Total espacios & 110.727 & 136.926 & 227.151 & $\mathbf{1 , 0 5 3}$ & $\mathbf{1 , 1 0 7}$ & 54.812 & 45.477 & 38.800 \\
\hline $\begin{array}{l}\text { Total } \\
\text { metropolitano }\end{array}$ & 4.238 .411 & 4.258 .278 & 4.371 .429 & $\mathbf{1 , 0 0 2}$ & $\mathbf{1 , 0 0 5}$ & & & 235.851 \\
\hline
\end{tabular}

\begin{tabular}{|l|l|c|}
\hline \multirow{4}{*}{ Destino emigrados Barcelona } & A la primera periferia & 62.828 \\
\cline { 2 - 3 } & Al entorno capitales segunda corona & 63.880 \\
\cline { 2 - 3 } & A resto de Catalunya & 43.594 \\
\cline { 2 - 3 } & Al resto de España & 26.749 \\
\cline { 2 - 3 } & A municipios 2a residencia & 38.800 \\
\hline
\end{tabular}

Fuente: estudio de saldos migratorios entre Barcelona y su Región, Mancomunitat Metropolitana de Municipis, y censos de población, Institut d'Estadítica de Catalunya.

Figura 6. Ciudad concentrada y ciudad dispersa en la región metropolitana de Barcelona.

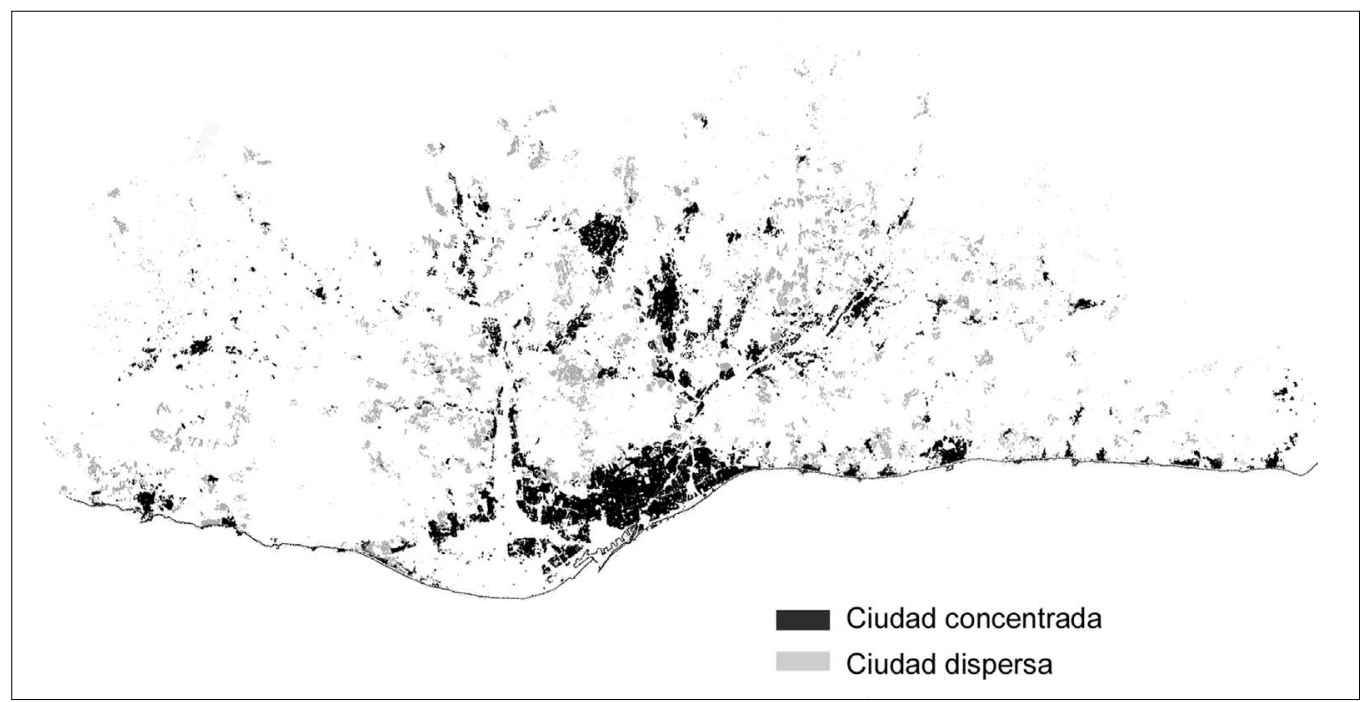

Fuente: Font y Llop (1999). 
Figura 7. Red de autopistas y zonas de segunda residencia en la región metropolitana de Barcelona.

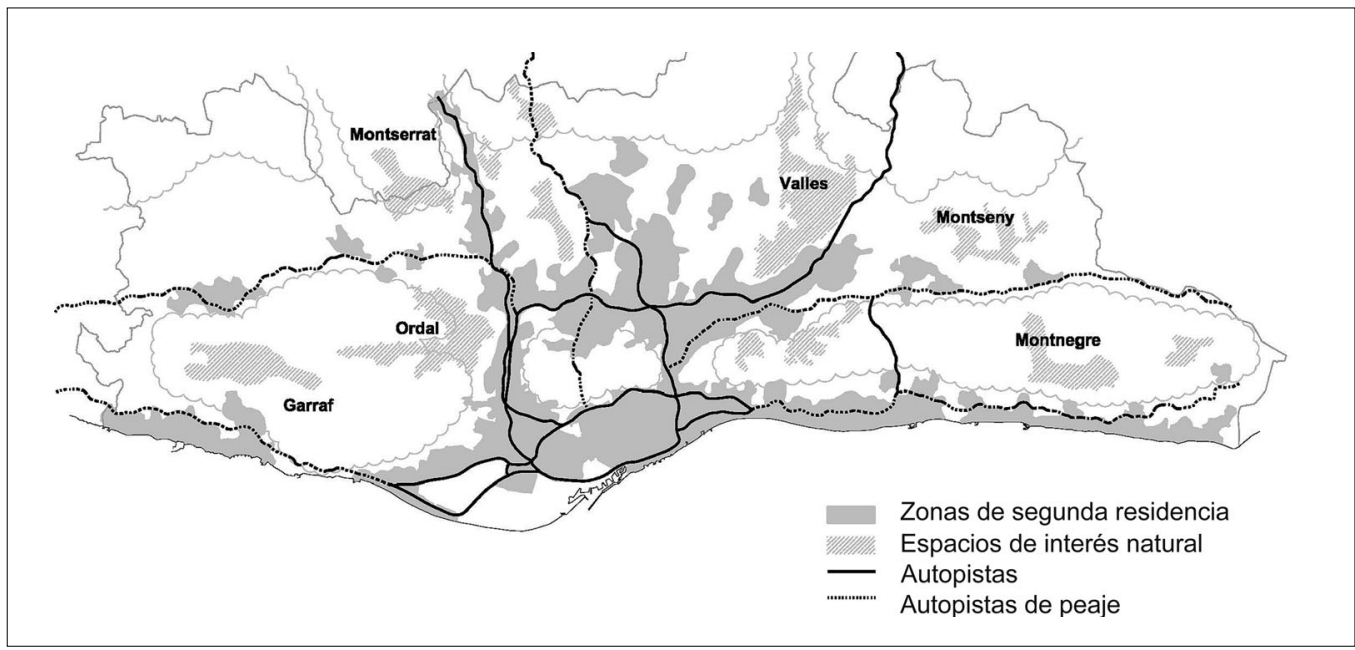

Fuente: Herce (2004).

$18 \%$ ha tenido como destino municipios de la Región, en lugares donde se concentraban las segundas residencias de clases populares (tabla 8).

Muchas de las ventas de pisos en Barcelona y en la Primera Corona han sido producto de la combinación entre la capitalización del ahorro que suponían las jubilaciones anticipadas y la disponibilidad de una vivienda de segunda residencia en el área; muchos Ayuntamientos saben del incremento de las solicitudes de sus servicios de asistencia que ello ha supuesto.

Para entender mejor el fenómeno hay que recordar la importancia que tiene en España el régimen de propiedad de vivienda, y cómo la clase trabajadora emigrada a las grandes ciudades en la posguerra destinó a ella la mayor parte de sus ingresos, transformados en casi el único mecanismo de ahorro. Ello creó hábitos que tuvieron continuidad con la construcción de segundas viviendas en zonas de bajo valor del precio del suelo, normalmente de autoconstrucción y con fuerte inversión de tiempo en fines de semana (Herce, 1975). Y hay que recordar, igualmente, la fuerte cantidad de jubilaciones anticipadas que han acompañado a la destrucción de empleo industrial y a la transformación de la base económica, así como la progresiva pérdida del valor adquisitivo de las pensiones en los últimos años.

Esos municipios se concentran, en general, en cuatro áreas territoriales ubicadas en las sierras del
Garraf (al sur), en la del Litoral-Montnegre (al norte) y en las estribaciones de las sierras interiores de Montserrat-Sant Llorens y Vallés-Montseny, todos ubicados en las zonas de peor conectividad. En el último de esos espacios es donde el crecimiento demográfico ha sido mayor, con tasas de hasta el $7 \%$ anual acumulativo, y un análisis más detallado de él puede tomarse como arquetipo de cualquiera de los otros espacios.

El desplazamiento de bolsas de población a esas áreas, unido al hecho de que continúan siendo las de menor conectividad metropolitana, significa una pérdida importante de renta de posición para esos ciudadanos. A pesar de la existencia de equipamientos sociales y sanitarios distribuidos por el territorio, la mayor dependencia respecto a Barcelona en cuanto a actividades de ocio, culturales y de determinados servicios, unida a la inexistencia de transporte colectivo en esas áreas, aumenta su grado de aislamiento o cuanto menos de mayor coste de la conectividad.

Además, la Región Metropolitana de Barcelona tiene un alto nivel de imposición de peajes en sus vías básicas; cinco de los siete accesos al centro por vías de alta capacidad tienen establecidos peajes. Ello encarece los costes de conexión de los espacios citados, ya de por sí con altos costes de desplazamiento y con dependencia del vehículo privado; son altamente expresivos al respecto los datos que se acompañan de la distribución de la movilidad en diversos 
modos de transporte y las cifras de utilización de los mismos para viajes obligados en cada uno de los ámbitos metropolitanos: su conversión en términos monetarios es un ejercicio sencillo.

No se pretende decir que el peaje haya actuado como discriminador negativo de esas áreas; por el contrario, se puede detectar una cierta descentralización de la residencia de clases media-altas sobre los espacios abiertos por los nuevos túneles de peaje (Sant Cugat en el Vallés, Sitges-Vilanova en el Garraf), peajes por otro lado más altos de lo normal que colaboran de alguna manera a la creación de zonas de autosegregación espacial de esas clases sociales.

Pero el resto del espacio metropolitano también depende del peaje o utiliza vías alternativas de mayor tiempo de recorrido, y ello castiga en mayor medida a las rentas bajas y a los espacios geográficamente marginados por la red; sus ciudadanos perciben una menor renta indirecta que los de Barcelona, que tiene proximidad a todos los servicios, alternativas de uso de todos los medios de transporte y ausencia de peajes en sus movimientos internos.

\section{El coste de la dispersión: el acceso a los servicios}

La Ciudad Metropolitana es en la actualidad enormemente dependiente del transporte privado, con un sistema de transporte colectivo deficitario fuera del ámbito central, y de difícil corrección por mejora de la oferta periférica, dada la baja densidad de sus asentamientos. En la actualidad, la oferta metropolitana en vehículo privado, medida por el indicador que combina número de coches aforados por capacidad viaria en la red básica, es de 28.600 millones de vehículos por kilómetro, frente a un total de 1.100 en la oferta de transporte colectivo en todos sus modos: no es un indicador concluyente en sí mismo, por cuanto la red viaria soporta casi todos los modos y está destinada también a otras muchas funciones, y en todas las grandes ciudades existe una desproporción grande entre ambos niveles de oferta, pero en el caso del Área de Barcelona ésta alcanza un valor superior (Col-legi d'Enginyers Industrials de Catalunya, 2003).
Y no sólo el transporte; el actual modelo de desarrollo basado en la producción constante de infraestructuras con indiscriminada ampliación de las redes sobre el territorio tiene como consecuencia la generación de una ciudad dispersa, con un altísimo coste de suministro de los servicios básicos a la población de menores recursos.

Por otro lado, las alteraciones producidas en las formas de organización de la producción llevan hacia una cada vez mayor internalización por el trabajador de costes que antes eran asumidos por las empresas; la creciente organización del trabajo sobre la base de pequeñas unidades autónomas -cuando no individuales- pone en creciente valor los costes de conexión, transporte y de acceso a los servicios, y, consecuentemente, pone en primer plano el papel discriminador de los distintos territorios que tiene la distribución espacial de la accesibilidad, de la disponibilidad de sistemas de transporte y de la conectividad a las redes de telecomunicación. La ausencia de esta conexión, o su coste mucho más elevado que para el resto de los ciudadanos, implica también una paulatina pérdida de oportunidades laborales e incrementa la situación de marginación de los ciudadanos mal conectados a las redes.

Es ya conocido que las infraestructuras constituyen el soporte económico de nuestros territorios, constituyéndose en principal sector de inversión y condicionante de su desarrollo, incluso como factor determinante de la localización económica. Pero lo que se pretende demostrar es que lo que está cambiando aceleradamente es su función de suministradoras de servicios, mostrándose más claramente la capacidad que tienen sus redes de discriminar el espacio y crear, potencialmente, desigualdades sociales.

La forma de las redes, la cobertura espacial que produce, las facilidades de accesos a ellas y los costes de ese acceso serán en el futuro un discriminador espacial y social, y la ausencia de densidad se muestra como el principal enemigo de la extensión de las redes, como lo muestran los ámbitos de cobertura de las recientes redes de cable.

\section{Conclusión}

Es cada vez más evidente que la forma de las redes, la cobertura espacial que producen, las facili- 
dades de accesos a ellas y los costes de ese acceso comienzan a ser un importantísimo discriminador territorial y social.

Es por tanto preciso crear un estado de opinión que muestre que la sociedad de la dispersión de los servicios y la extensión de las redes no sólo es la sociedad del despilfarro (lo que comienza a ser admitido), sino que fundamentalmente es la sociedad de la desigualdad; el modelo de ocupación del territorio que produce sólo es posible con profundas diferencias en el acceso a los servicios, bien por diferentes gradientes en su producción espacial, bien por precisar de una financiación privada que establece diferencias de acceso en función de la capacidad económica de las personas. O lo que todavía es más paradójico, obliga a los ciudadanos de la periferia a pagar por servicios urbanos que son gratuitos o más baratos para los ciudadanos del espacio central, incrementando sus diferencias de renta.

La quiebra de ese modelo sólo puede venir de ser capaces de entender que sólo en la concentración y densidad puede haber posibilidad de atención a las necesidades de los ciudadanos, y que es preciso distinguir un territorio a dotar de servicios urbanísticos de un territorio a proteger de ellos. El discurso no es fácil porque es contrario a otro que se enmascara con conceptos aparentemente "progresistas", como los de reequilibrio territorial, ruralización de lo urbano, etc.

Frente a ese enfoque, sólo cabe el de entender el territorio como un espacio con diferentes gradientes de conectividad y de disponibilidad de servicios que ofrece, por tanto, diferentes posibilidades de uso económico y social. En el territorio de las redes no existe un centro y una periferia, sino que aquellos y éstas se solapan en el espacio, definiéndose su centralidad o su marginalidad por su disponibilidad de conectividad, accesibilidad y servicios.

Los efectos perniciosos de las políticas aparentemente inocuas, e incluso igualitarias, de generalización de la accesibilidad o extensión indiscriminada de las redes (que a menudo sólo esconden la extensión de plusvalía urbana), llevan a una clara especialización del espacio, donde son los costes de conexión a las redes, y no su simple existencia, los que actúan de discriminadores; la financiación de esas redes por métodos de concesión y peaje agravan las diferencias espaciales en la medida que dañan de muy distinta forma a las diferentes economías familiares.

Y, en el extremo, esa indiscriminada ocupación del territorio se traduce, como lo muestra el ejemplo analizado, en un incremento del precio del suelo y en un consecuente incremento del precio de la vivienda que deja a amplias capas de la población fuera del mercado, incrementando los procesos de informalidad en la producción de viviendas y de posible marginalidad social.

Las políticas urbanísticas y de inversión en infraestructuras sólo pueden tener legitimidad sobre la base del control público del uso del territorio y de la distribución de niveles de accesibilidad y conexión a las redes, verdadero sustento de la igualdad y la desigualdad, porque las deficiencias y los bajos niveles de conectividad se traducen en costes que cada vez más internaliza el usuario más desfavorecido. El crecimiento económico sólo alcanza justificación si se traduce en una más igualitaria distribución de los servicios urbanísticos y de las redes de infraestructuras, cuyas condiciones necesarias son, también, la compacidad y la densidad, y el transporte público y eficaz, que es el mecanismo más potente de facilitar el acceso a los servicios.

\section{Referencias bibliográficas}

Área de Mobilitat, Transport i Circulació del Ajuntament de Barcelona (varios años). Datos anuales de flujos vehiculares. Barcelona: Área de Mobilitat, Transport i Circulació del Ajuntament de Barcelona.

Borja, J. et al. (2003). El urbanismo de las ciudades españolas: una visión crítica. Barcelona: Edicions UPC.

Col-legi d'Enginyers Industrials de Catalunya (2003). Informe sobre el transport a Catalunya. Barcelona: www. eic. es

Dupuy, G. (1991). L’urbanisme des réseaux. París: Armand Colin.

(1995) Territoires de l'automobile. París: Antrophos.

Ferrer, A. (1992). "El proceso de terciarización en Barcelona". Papers, 12: 47-57.

(2001). "La producción de oficinas".

Barcelona Economía, 2: 8-12. 
Font, A.A. y C. Llop (1999). La construcción del territorio metropolitano: morfogénesis de la región de Barcelona. Barcelona: Mancomunitat Metropolitana de Municipis.

Herce, M. (1975). "El consumo del espacio por urbanizaciones de segunda residencia". Ciudady Territorio 4, 75: 45-57.

(1983). "La utilización de indicadores topológicos en el análisis de las redes de transporte". Documents d'anàlisi geogràfica, 3: 3-45. (1998). "Transformaciones topológicas de la red de transportes y cambios de localización de actividades". XX Congreso de Ingeniería Civil. Madrid: Colegio de Ingenieros de Caminos, Canales y Puertos de España.

(2002a). "Tendencies de urbanizatció en la ciutat metropolitana". Materials del
Llobregat, 8: 37-53.

(2002b). La ingeniería en la evolución de la urbanistica. Barcelona: Edicions UPC. (2004). "Barcelona: Accesibility changes and metropolitan transformations". Built Environement, 30: 127-138.

Mancomunitat Metropolitana de Munipis (M.M.M.) (1995). Dinámicas metropolitanas en el área y región de Barcelona. Barcelona: M.M.M.

Mayer, R (1965). "Prix du sol et prix du temps: essai sur la formation des prix fonciers". Bulletin du P.C.M., 10, 65: 9-37.

Roca Cladera, J. (1987). Manual de valoraciones inmobiliarias. Barcelona: Ariel.

Serratosa, A. et al. (1998). Dades per al Pla territorial de la Regió Metropolitana de Barcelona. Generalitat de Catalunya: www.gencat.es/ptop/ptmb. 